\title{
Three months after severe head injury: psychiatric and social impact on relatives
}

\author{
MARTIN G LIVINGSTON, D NEIL BROOKS, MICHAEL R BOND \\ From the Department of Psychological Medicine, University of Glasgow, Glasgow UK
}

SUMMARY Female relatives of defined groups of consecutive male minor and severe head injury victims were seen at home 3 months after the injury. The relatives of the severely injured suffered significant psychiatric morbidity compared to the minor head injury relatives. They also showed poorer functioning in social roles associated with the home. There was no difference in the vulnerability of either wives or mothers of the head injury victims. It is argued that there is a need for support for the relatives of those who have suffered severe brain injury.

The annual admission rate for head injury in the United Kingdom is approximately 300 per 100,000 of the population. ${ }^{1}$ One in 20 of these injuries warrants transfer to a specialised neurosurgical service. ${ }^{2}$ Mortality may be as high as $50 \% .^{3}$ Each year the survivors swell the statistics for the chronically disabled by some 1,500 persons. ${ }^{4}$ These are mostly young men of lower socio-economic status. ${ }^{1}$ Physical handicaps, ${ }^{5}$ cognitive $^{6}{ }^{6}$ social $^{78}$ and psychiatric sequelae $^{y}{ }^{10}$ are often present with differential rates of recovery and variable outcome." The majority of these individuals return home. In many cases a relative has to cope with diverse problems with little support. It has been suggested that relatives cope by adopting defensive strategies such as denial. ${ }^{12} 13$

The relatives' major complaint about the head injured is of behavioural difficulties..$^{14-16}$ Concern is often expressed about lack of temper control and affective changes, with physical handicaps being a less frequent cause for complaint.

Rosenbaum and Najenson ${ }^{17}$ compared wives of men who had suffered a military head injury with the wives of paraplegics and staff members. Depression was more frequently reported by the head injured wives. Oddy, et al ${ }^{15}$ using the Wakefield Depression Inventory ${ }^{18}$ also found a high incidence of depression early on in the recovery phase, associated with the relatives' perception of the patients' problems. Unfortunately the sample was skewed towards the higher socio-economic categories and

Address for reprint requests: Dr MG Livingston, Dept of Psychological Medicine, University of Glasgow, 6 Whittinghame Gardens, Great Western Rd, Glasgow G12 0AA, UK those aged over 40 years were not represented.

Brooks and McKinlay ${ }^{14}$ using a seven point self rating of stress demonstrated that relatives remaine $\bar{\partial}$

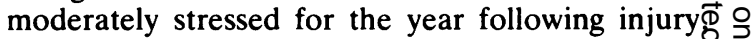
associated with the relatives perception of the patients' problem. Physical sequelae did not seemf cs associated with high stress reports by relatives.

Social, as well as emotional, consequences havee been studied. Rosenbaum and Najenson ${ }^{17}$ reporte greater "disruption" amongst the wives of the heaळ" injured compared with controls. Oddy et al ${ }^{7}$ using $\mathrm{a}^{+}$ semi-structured social adjustment schedule did not find increased family friction 6 months after injury. They reported the presence of friction however 2 years after injury in a rehabilitation sample. ${ }^{20}$ Oddy and Humphrey ${ }^{21}$ assessed social adjustment sequentially in the year following severe head injury. Despite a return to work by most patients, a full resumption of social activities had not taken place although family relationships had recovered.

At present there is no reliable method of providing a comprehensive assessment of patients' outcome, in all its facets, after head injury. Control groups, where used, have varied between staff relatives, ${ }^{17}$ limb trauma patients and relatives, ${ }^{21}$ paraplegics and their relatives ${ }^{17}$ and one study used a relatives' retrospective report of the premorbid status of another group of head injured patients. ${ }^{20}$ Decisions about which control groups to use in head injury research depend on the nature of the questions posed by the study and on the need to obtain a group with similar age, sex, social class and possibly lifestyle to those who sustain a severe head injury. ${ }^{23}$

It was felt that there was insufficient detailed and 
objective information available on the psychiatric and social outcome of relatives who live with a brain injured patient following discharge from hospital. The study was set up to provide such information, and its relationship to patients' functioning.

\section{Method}

\section{Aims}

The present study was set up to answer three questions. (1) Do relatives of severe head injury victims suffer significant psychiatric disturbance? (2) Is the relatives' social functioning related to the severity of the injury? (3) Which relationship, marital or parental, is more vulnerable?

\section{Assessment procedure}

In this study, severe head injury patients and their relatives $(n=42)$ were seen at 3 months after injury. The comparison group was also assessed at a similar time. Assessments took place in the family home. Earlier assessment was avoided because of the likelihood of picking up a crisis reaction during the period when the patient's life is possibly in danger.

\section{Population}

The patients were consecutive male, severe, blunt head injury victims who had been admitted to the neurosurgical facility serving the West of Scotland. A severe head injury consisted of having a post traumatic amnesia (PTA) of greater than $\mathbf{4 8}$ hours (defined as the time elapsed between injury and continuous recovery of memory), assessed retrospectively ${ }^{23}$ and a Glasgow Coma Score (GCS) of less than 8 recorded on admission. ${ }^{24}$ Two thirds of the patients had recorded such a score for longer than 6 hours. The PTA scores for the severely injured patients are shown in table 1 .

The female relative seen was the wife of a married man, the mother of a single man and, on three occasions, a daughter. Relatives had to live with the patient. The assumption made was that such relatives were the main care-givers. On questioning, all agreed that this was, in fact, the case.

A control group of consecutive mild male head injury admissions and a similarly defined female relative was seen $(n=41)$. Mild head injuries were defined as those requiring admission to the short stay area of a busy district general hospital for less than $\mathbf{4 8}$ hours. The aim was to control for premorbid personality, demographic factors and lifestyle. PTA was too brief in these men to be accurately recorded retrospectively.

Table 1 Post-traumatic amnesia duration in severely injured men

\begin{tabular}{lr}
\hline Post-Traumatic Amnesia & $N$ \\
\hline$>48$ hours & 9 \\
$>1$ week & 16 \\
$>1$ month & 14 \\
$>3$ months & 3 \\
\hline
\end{tabular}

\section{Demography}

There were no significant differences using independent sample $t$ tests between patients' and relatives' ages in each of the samples. This is shown in tables 2 and 3 .

The social class distribution was similar in both patient (based on their occupation) and relative (based on male head of household's occupation) samples. Comparisons were made using the chi-squared test but because of the very small numbers in social classes I and II, social classes I, II and III were considered together as were classes IV and $V$. Tables 4 and 5 illustrate this.

\section{Patients' measures}

The patients' outcome was assessed by the well-established Glasgow Outcome Scale (GOS). ${ }^{25}$ Table 6 shows the outcome categories at three months in both the mildly and severely injured patient populations. The severely injured clearly have a poorer outcome (Mann-Whitney $U=105 \cdot 5$, $\mathrm{p}<0.0001)$.

In order to assess clinical outcome in several different areas, a standardised assessment procedure was devised. This involved assessments of symptomatic complaints,

Table 2 Comparison of patients' ages

\begin{tabular}{lllllll}
\hline Variable & $N$ & $\begin{array}{l}\text { Range } \\
(y r)\end{array}$ & $\begin{array}{l}\text { Mean } \\
(y r)\end{array}$ & $S D$ & $t$ & $\begin{array}{l}\text { 2-tail } \\
\text { Probability }\end{array}$ \\
\hline $\begin{array}{l}\text { Patient s age } \\
\text { Mildly injured }\end{array}$ & 41 & $16-58$ & 32.83 & 12.91 & 1.30 & 0.20 \\
Severely injured & 42 & $16-64$ & 36.40 & 15.99 & & \\
\hline
\end{tabular}

Table 3 Relatives' ages

\begin{tabular}{lllllll}
\hline Variable & $N$ & $\begin{array}{l}\text { Range } \\
(y r)\end{array}$ & $\begin{array}{l}\text { Mean } \\
(y r)\end{array}$ & $S D$ & $t$ & $\begin{array}{l}\text { 2-tail } \\
\text { probability }\end{array}$ \\
\hline $\begin{array}{l}\text { Relatives' ages } \\
\text { Mildly injured }\end{array}$ & 41 & $19-64$ & 42.0 & 14.1 & & \\
Severely injured & 42 & $25-65$ & 46.5 & 10.5 & 1.67 & 0.10 \\
\hline
\end{tabular}

Table 4 Comparison of patients' social class

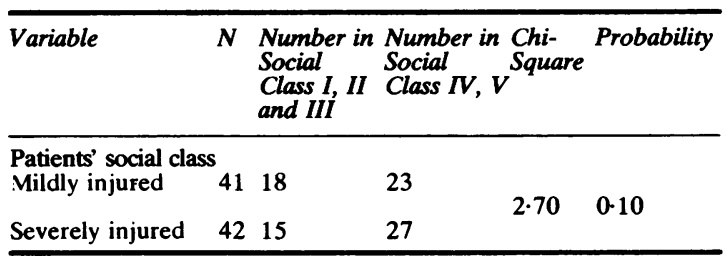

Table 5 Relatives' social class

\begin{tabular}{llllll}
\hline Variable & $N$ & $\begin{array}{l}\text { Social } \\
\text { Class I } \\
\text { and II }\end{array}$ & $\begin{array}{l}\text { Social } \\
\text { Class III, } \\
\text { IV \& } V\end{array}$ & $\begin{array}{l}\text { Chi- } \\
\text { Square }\end{array}$ & Probability \\
\hline Mildly injured & 41 & 25 & 16 & 2.72 & 0.10 \\
Severely injured & 42 & 17 & 25 & & \\
\hline
\end{tabular}


Table 6 Patients' scores on the Glasgow Outcome Scale

\begin{tabular}{lll}
\hline $\begin{array}{l}\text { Glasgow Outcome Scale } \\
\text { Score (GOS) }\end{array}$ & $\begin{array}{l}(n=41) \\
\text { Mildly injured }\end{array}$ & $\begin{array}{l}(n=42) \\
\text { Severely injured }\end{array}$ \\
\hline 0 & 26 & 2 \\
1 & 13 & 5 \\
2 & 2 & 7 \\
3 & 0 & 17 \\
4 & 0 & 7 \\
5 & 0 & 4 \\
\hline
\end{tabular}

Mann-Whitney $U=105.5, p<0.0001$

physical outcome, activities of daily living, cognitive functioning, personality change and occupational status. Scoring was generally on a three point scale, (absent, present in moderate severity, present and severe). There was no mild category, in order to increase specificity and reliability in a clinical area where many complaints are highly subjective. Inter-rater reliability, assessed in 26 joint interviews, was above $70 \%$ for all ratings (Cohen's Weighted Kappa). ${ }^{26}$

\section{Relatives' measures}

Relatives' psychiatric function was assessed by means of the GHQ-60.27 A rating of mood state was provided by the Leeds General Scales for anxiety and depression. ${ }^{28}$ Both scales have well demonstrated reliability and validity. Population norms exist and the scales have high acceptability in the community. The cut-off score chosen for assessing psychiatric casesness by means of the GHQ was 13 or above. Concurrent assessment with the $\mathrm{PSE}^{29}$ in 20 consecutive cases drawn from this and a follow-up study indicated that the score chosen provided satisfactory sensitivity $(80 \%)$ and specificity $(88.8 \%)$. The designated cut-off score of 7 was used with the Leeds scales.

Social functioning was assessed by means of Weissman's social adjustment schedule in the self-report format. This conceptualised social functioning in terms of functioning within defined social roles. ${ }^{30}$ The scale has good psychometric properties and US norms are available. It has been used satisfactorily in the UK by Cooper $e^{2} a^{31}$ and by McCreadie and Barron. ${ }^{32}$

The control group relatives were compared with Weissman's US community sample of women. ${ }^{30}$ No statistically significant differences were demonstrated at the $5 \%$ level ( 2 tailed independent sample $t$ tests).

The relatives' perception of the burden of living with the patient was assessed by a specially formulated perceived burden scale. This consisted of 25 questions, answered on a presence/absence basis drawn from those used in a previous study. ${ }^{14}$ The questions chosen were those which most frequently elicited a positive response. Again inter-rater reliability, assessed throughout the study, was reasonable being above 0.61 in all questions (Cohen's Kappa).

\section{Results}

(1) Do relatives of men who have had a severe head injury suffer more psychiatric disturbance than relatives of men who have had a minor head injury? The numbers of relatives who scored within the "caseness" zones on the GHQ and Leeds scales were assessed. Caseness refers to those individuals whom the rating scales would predict were likely to be psychiatric cases, that is they scored greater than 12 on the GHQ and/or greater than 7 on the Leeds Scales. Table 7 illustrates that there were significant differences (Chi-square). More cases defined by the GHQ and the Leeds Anxiety scales are recorded amongst the severely injured, but the difference between the two populations on the Leeds Depression Scale is not significant. A similar pattern is found when comparing raw scores on these instruments.

These results indicate that a significant proportion of the relatives of severely injured men have psychiatric disturbance compared with the controp population. The major disturbance is affective and indeed is anxiety based rather than depressive. In addition, examination of scores in the GHQ sub scales reveals statistically significant differences in scores on the anxiety/insomnia $(t=3.28 \mathrm{p}<0.001)$, and the social dysfunction $(t=2.51 \mathrm{p}<0.01$ subscales). The questions in the latter scale essentially test ability to cope. The relatives did not differ however, on the somatic complaints or severe depression subscales.

The perceived burden rating of the two groups of relatives was 1.83 (SD 2.23) for the mildly injured and 7.24 (SD 4.91) for the severely injured. This difference is statistically significant at the 0.001 level (2-tailed $t$ test). The relatives therefore, are very different in terms of their subjective rating of the patients' complaints.

Table 7 Caseness in relatives

\begin{tabular}{|c|c|c|c|c|c|c|}
\hline Variable & $N$ & Cases & Non-Cases & Cut-off Score & Chi-Square & Probability \\
\hline $\begin{array}{l}\text { GHQ } \\
\text { Mildly Injured } \\
\text { Severely Injured } \\
\text { LEEDS ANXIETY SCALE }\end{array}$ & $\begin{array}{l}37 \\
42\end{array}$ & $\begin{array}{r}4 \\
24\end{array}$ & $\begin{array}{l}33 \\
18\end{array}$ & $>12$ & $8 \cdot 52$ & 0.00 \\
\hline $\begin{array}{l}\text { Mildly Injured } \\
\text { Severely Injured } \\
\text { LEEDS DEPRESSION SCALE }\end{array}$ & $\begin{array}{l}41 \\
42\end{array}$ & $\begin{array}{r}8 \\
19\end{array}$ & $\begin{array}{l}33 \\
23\end{array}$ & $>7$ & $5 \cdot 14$ & 0.02 \\
\hline $\begin{array}{l}\text { Mildly Injured } \\
\text { Severely Injured }\end{array}$ & $\begin{array}{l}41 \\
42\end{array}$ & $\begin{array}{l}3 \\
9\end{array}$ & $\begin{array}{l}38 \\
33\end{array}$ & $>7$ & $2 \cdot 23$ & $0 \cdot 13$ \\
\hline
\end{tabular}


(2) Do relatives of men who have had a severe head injury suffer more social dysfunction than relatives of men who have had a minor head injury?

A comparison of relatives' total scores on Weissman's Social Adjustment Schedule is shown together with functioning in each of the different social roles. The roles themselves need little further explanation except that work functioning includes domestic as well as remunerative occupation and family unit functioning refers to relationships with those who are related and living in the family home. Marital functioning and family unit functioning were significantly worse in the relatives of the severely injured $(t=1.77 \mathrm{p}<0.04, t=2.14 \mathrm{p}<0.01)$, and this is shown in table 8 . The indications here are of poorer adjustment in the relatives of the severely injured in social roles performed in the family home. Relationships with the family beyond the home, at work and in social and leisure activities are unaffected.

\section{(3) Does the pyschosocial outcome for relatives} depend on the nature of the relationship to the head injured patient?

Of the 42 relatives of the severely injured seen in this study 22 were wives of the patients and 16 were mothers. Amongst the mildly injured there were 23 wives and 15 mothers.

The levels of caseness on the GHQ and Leeds scales were no different when wives and mothers were compared in the severely injured population. Comparisons were next made between mothers and wives of the severely injured with their respective relative group in the control sample. Within the mothers' group, relatives of the severely injured displayed significantly higher Leeds Anxiety scores $(t=$
$2.08, \mathrm{p}<0.02$ ) but the levels of caseness on the GHQ and Leeds scales did not differ significantly (Chi-square). The mothers of the severely injured men did not differ significantly from the control mothers on social functioning, either globally or indeed in individual roles.

Within the wives' group the relatives of the severely injured had significantly higher GHQ scores $(t=1.69, \mathrm{p}<0.05)$ and Leeds Anxiety scores $(t=1.93, \mathrm{p}<0.03)$. They were more likely to be a GHQ case (Chi-square $=5.97, \mathrm{p}<0.01$ ) but not a Leeds Anxiety or Depression case. They did not differ in social adjustment, performing less adequately with the family at home, $(t=2 \cdot 14, \mathrm{p}<$ $0.01)$.

\section{Discussion}

These results show that there is a measurable psychiatric and social impact on the relatives of severe head injury victims three months after injury. The pattern of morbidity is one of mood disturbance together with social role dysfunction in roles performed in the family home. The mood disturbance is anxiety based. Forty-five percent of the relatives of the severely injured men score beyond the Leeds Anxiety caseness threshold. Fifty-seven percent do so on the GHQ, perhaps indicating that others are suffering a more generalised less specific disturbance. The case for a different outcome depending on relationship to the patient is less strong. The evidence here points to wives being more severely handicapped psychosocially compared to control wives than mothers compared to their controls.

These results are not in complete agreement with

Table 8 Relatives' social adjustment

\begin{tabular}{|c|c|c|c|c|c|}
\hline Variable & $N$ & Mean & $S D$ & $t$ & 1-Tail Probability \\
\hline \multicolumn{6}{|l|}{ Global social functioning } \\
\hline $\begin{array}{l}\text { Mildly injured } \\
\text { Severely injured } \\
\text { Work functioning }\end{array}$ & $\begin{array}{l}41 \\
42\end{array}$ & $\begin{array}{l}1.59 \\
1.67\end{array}$ & $\begin{array}{l}0.32 \\
0.34\end{array}$ & 1.05 & 0.15 \\
\hline Mildly injured & $\begin{array}{l}41 \\
40\end{array}$ & $\begin{array}{l}1 \cdot 34 \\
1 \cdot 43\end{array}$ & $\begin{array}{l}0.39 \\
0.39\end{array}$ & $1 \cdot 12$ & 0.13 \\
\hline $\begin{array}{l}\text { Social \& leisure functioning } \\
\text { Mildly injured } \\
\text { Severely injured } \\
\text { Functioning with the extended family }\end{array}$ & $\begin{array}{l}41 \\
42\end{array}$ & $\begin{array}{l}1.96 \\
1.97\end{array}$ & $\begin{array}{l}0.43 \\
0.46\end{array}$ & $1 \cdot 17$ & 0.46 \\
\hline $\begin{array}{l}\text { Mildly injured } \\
\text { Severely injured } \\
\text { Marital functioning }\end{array}$ & $\begin{array}{l}40 \\
38\end{array}$ & $\begin{array}{l}1.46 \\
1 \cdot 38\end{array}$ & $\begin{array}{l}0.46 \\
0.33\end{array}$ & 0.54 & 0.20 \\
\hline $\begin{array}{l}\text { Mildly injured } \\
\text { Severely injured } \\
\text { Parental functioning }\end{array}$ & $\begin{array}{l}34 \\
37\end{array}$ & $\begin{array}{l}1.74 \\
1.95\end{array}$ & $\begin{array}{l}0.54 \\
0.43\end{array}$ & 1.77 & 0.04 \\
\hline $\begin{array}{l}\text { Mildly injured } \\
\text { Severely injured } \\
\text { Family unit functioning }\end{array}$ & $\begin{array}{l}29 \\
28\end{array}$ & $\begin{array}{l}1 \cdot 53 \\
1 \cdot 36\end{array}$ & $\begin{array}{l}0.50 \\
0.47\end{array}$ & $1 \cdot 28$ & $0 \cdot 10$ \\
\hline $\begin{array}{l}\text { Mildly injured } \\
\text { Severely injured }\end{array}$ & $\begin{array}{l}38 \\
39\end{array}$ & $\begin{array}{l}1.43 \\
1.74\end{array}$ & $\begin{array}{l}0.54 \\
0.73\end{array}$ & $2 \cdot 14$ & 0.01 \\
\hline
\end{tabular}


the current literature. Depression assessed either by the Leeds Depression Scale or by the GHQ subscale was not a major problem in this sample of relatives. This contrasts with the findings of Oddy et al ${ }^{15}$ and the Israeli group. ${ }^{17}$ In the former study, an instrument was used which has now been modified. The atypical population makes comparison difficult and in addition, Oddy et al did not use a control population. The Israeli study is based on work in a military rehabilitation centre. The small numbers involved in this study and the choice of control groups are serious methodological flaws.

The social adjustment results are even harder to compare with the literature. Rosenbaum and Najenson $^{17}$ report disruption amongst head injured wives. Oddy et al $^{15}$ did not find family friction in their study. Their assessment took place however, rather later (at 6 months), than in the present study, and in a milder and generally different population from the one studied here.

The results of this study support the idea that functioning in the family home was impaired three months after injury. Problems seem to be developing in marital relationships and in relationships with other family members who live in the family home. Social and leisure activities, functioning at work as a parent and with the extended family were not impaired. The difficulties would therefore, seem to be fairly well circumscribed. They do not extend for example, into recreational and occupational activity.

However, the differences between the relatives of the severely injured and those of the mildly injured in terms of social functioning, are not striking. The overriding impression despite early difficulties in marital and close family relationships is of relatives continuing to function ably in a number of different social roles.

There has been no systematic study in the literature of which relationships are more vulnerable to the stresses imposed by head injury patients. Panting and Merry ${ }^{33}$ and Thomsen ${ }^{14}$ suggest that wives may be more vulnerable but Oddy et al ${ }^{15}$ suggest that there may be a greater impact on mothers. There was no evidence in this study to support the idea of a different pattern of psychosocial morbidity in either group of relatives. There was some evidence, however, indicating that wives sustained a poorer outcome.

In summary, the study provides evidence of a significant psychiatric and social impact on the relatives of men who have suffered a severe head injury when seen at home three months after the injury has taken place. Recovery from severe head injury particularly in terms of social reintegration of the individual has just begun.

This paper demonstrates the need for support for the relatives after severe head injury victims are discharged from hospital. These relatives may require help either for themselves or guidance in managing the patients. Perhaps it might be helpful to see these care-giving relatives as potential full-time nonprofessional therapists.

\section{References}

' Jennett B, MacMillan R. The epidemiology of head injury. Br Med J 1981;1:101-4.

2 Jennett B, Murray A, Carlin $J$ et al. Head injuries in three Scottish Neurosurgical Units. Scottish H.I Management Study. Br Med J 1979;2:955-8.

${ }^{3}$ Langfitt W. Measuring the outcome for head injuries. $J$ Neurosurg 1981;48:637-78.

${ }^{4}$ London PS. Some observations on the course of events after severe injuries to the head. Ann R Coll Surg Engl 1967;41:460-79.

5 Jennett B, Snoek J, Bond MR et al. Disability after severe head injury. Observations on the use of the Glasgow Outcome Scale. J Neurol Neurosurg Psychiatry 1981;44:285-93.

- Brooks DN, Aughton ME. Cognitive recovery during $\infty$ the first year after severe blunt head injury. Int $J$ of Rehabil Med 1979;1:166-72.

${ }^{7}$ Oddy M, Humphrey M, Uttley D. Subjective impain ment and social recovery after closed head injury. Neurol Neurosurg Psychiatry 1978a;41:611-6.

${ }^{8}$ Brooks N. Head Injury and The Family. In: Brooks N ed. Closed Head Injury: Psychological, Social ang Family Consequences. Oxford: Oxford Universit Press, 1984:123-47.

'Lishman WA. The psychiatric sequelae of head injury: review. Psychol Med 1973;3:304-18.

${ }^{10}$ Bond MR. The Psychiatry of Closed Head Injury. In: Brooks N, ed. Closed Head Injury: Psychological, Social and Family Consequences. Oxford: Oxford University Press, 1984: 148-78.

" Bond MR. Stages of recovery from severe head injury with special reference to late outcome. Int J of Rehabil Med 1979;1:155-9.

12 Romano MD. Family response to traumatic head injury. Scand J of Rehabil Med 1974;6:1-4.

${ }^{13}$ Lezak MD. Living with the charactereologically altered brain injured patient. Clin Psychiatry 1978;39:592-8.

14 Thomsen IV. The patient with severe head injury and his family. Scand J of Rehabil Med 1974;6 (4):180-3.

is Oddy M, Humphrey M, Uttley D. Stresses upon the relatives of head injured patients. $\mathrm{Br} J$ Psychiatry 1978b;133:507-13.

${ }^{16}$ McKinlay WW, Brooks DN, Bond MR et al. The short term outcome of severe blunt head injury as reported by relatives of the injured persons. J Neurol Neurosurg Psychiatry 1981;44:527-33.

17 Rosenbaum M, Najenson T. Changes in life patterns and symptoms of low mood as reported by wives of severely brain injured soldiers.J Consult Clin Psychol $\mathrm{N}$ 1976;44(0):881-5.

${ }^{18}$ Snaith RP, Ahmed SN, Mehta S et al. Assessment of the 
severity of primary depressive illness. Psychol Med 1971;1:143-9.

${ }^{19}$ Brooks DN, McKinlay WW. Personality and behavioural changes after severe blunt head injury-a relative's view. J Neurol Neurosurg Psychiatry 1983;46:336-44.

${ }^{20}$ Weddell R, Oddy M, Jenkins D. Social adjustment after rehabilitation: a two year follow-up of patients with severe head injury. Psychol Med 1980;10:257-63.

${ }^{21}$ Oddy $M$, Humphrey $M$. Social recovery during the year following severe head injury. J Neurol Neurosurg Psychiatry 1980;43:798-802.

${ }^{22}$ McKinlay WW, Brooks DN. Methodological problems in assessing psychosocial recovery following severe head injury. J Clin Neuropsychol 1984;6 (1):87-99.

${ }^{23}$ Russell WR. Cerebral involvement in head injury-a study based on the examination of 200 cases. Brain 1932;55:549-603.

${ }^{24}$ Teasdale G, Jennett B. Assessment of coma and impaired consciousness. A practical scale. Lancet 1974;ii:81-4.

2s Jennett B, Bond MR. Assessment of outcome after severe brain damage. Lancet $1975 ; \mathrm{i}: 480-4$.

${ }^{26}$ Cohen J. Weighted Kappa: nominal scale agreement with provision for scaled disagreement or partial credit. Psychol Bull 1968;70:213-20.

${ }^{27}$ Goldberg D. Manual of the General Health Questionnaire. Windsor: NFER Publishing Co, 1978.

${ }^{28}$ Snaith RP, Bridge GWK, Hamilton M. The Leeds Scale for the self-assessment of anxiety and depression. $\mathrm{Br} J$ Psychiatry 1976;128:156-65.

${ }^{24}$ Wing JK, Mann SA, Leff JP et al. The concept of a case in psychiatric population surveys. Psychol Med 1978;8:203-17.

${ }^{30}$ Weissman MM, Prusoff BA, Thompson WD et al. Social adjustment by self-report in a community sample and in psychiatric outpatients. J Nerv Ment Dis 1978;166 (5):317-26.

${ }^{31}$ Cooper P, Osborn M, Gath D et al. Evaluation of a modified self-report measure of self-adjustment. $\mathrm{Br} \mathrm{J}$ Psychiatry 1982;144:68-75.

${ }^{32}$ McCreadie RG, Barron ET. The Nithsdale Schizophrenia Survey IV Social Adjustment by Self-Report. Br J Psychiatry 1984; 144:547-50.

${ }^{33}$ Panting A, Merry P. The long term rehabilitation of severe head injuries with particular reference to the need for social and medical support for the relatives' family. Rehabilitation 1972;38:33-37. 